\title{
Transplante autólogo de células mononucleares da medula óssea em úlcera de córnea experimental em cães
}

\author{
Bone marrow mononuclear cells autotransplant in experimental corneal ulcer in dogs
}

\author{
Guilherme Kanciukaitis Tognoli ${ }^{\mathrm{I}}$ Débora Cristina Olsson ${ }^{\mathrm{II}}$ Danieli Brolo Martins ${ }^{\mathrm{II}}$ \\ Eduardo de Bastos Santos JúniorII Fabiano Zanini Salbego"II Graziela Kopinits de Oliveira ${ }^{\text {II }}$

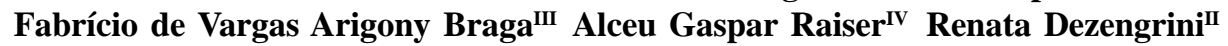 \\ Fernando Silvério Ferreira da Cruz ${ }^{\mathrm{II}}$ Márcio Botelho de Castrov \\ Mariana Carvalho RosaVI ${ }^{\text {Adriano Bonfim Carregaro }}{ }^{\text {IV }}$ Ney Luis Pippi ${ }^{\text {IV }}$
}

\section{RESUMO}

As células mononucleares (CM) da medula óssea (MO) despertam grande interesse nas pesquisas sobre regeneração tecidual. O limbo é a fonte de células-tronco (CT) para repor ceratócitos lesados e uma disfunção destas é denominada deficiência límbica. Essa condição é desenvolvida por diversas afecções, sendo que a queimadura por base é a mais comum. A fim de confirmar a presença das CM da MO transplantadas, a ocorrência de quimiotaxia destas e comparar histopatologicamente os grupos tratado e controle, utilizou-se um modelo experimental de úlcera de córnea associado ao autotransplante de CM. Para tanto, 16 cães machos ou fêmeas, sem raça definida, foram submetidos à úlcera experimental de córnea com papel filtro embebido em hidróxido de sódio (NaOH). Após as lesões, os animais foram submetidos a transplante subconjuntival de CM da MO, previamente marcadas com nanocristais. A avaliação pós-operatória foi realizada por imunofluorescência no sexto dia após o transplante e por histopatologia passados 15 dias do procedimento, quando foi possível notar que as CM fixaram-se na região lesionada, não sofreram quimiotaxia $e$, apesar de diminuírem a inflamação, não auxiliaram o processo de cicatrização corneana a curto prazo. Assim, sugerem-se estudos adicionais no transplante de CM da MO na cicatrização da córnea.

Palavras-chave: célula-tronco, medula óssea, fração mononuclear, úlcera de córnea, hidróxido de sódio, cão.

\begin{abstract}
Bone marrow (BM) mononuclear cells (MC) are a great subject in tissual regeneration. The main stem cell source to the eye is the limbus. Theses cells replace injured corneal cells, however, if the limbal stem cells are not functional, a limbal deficiency with concomitant conjunctivalization takes place. This pathological condition can be caused for several reasons, in which alkali burns are the most common. To conduct a research about transplanted $B M M C$ presence, the cells homing and to histopathologically compare the treated and sham group, an experimental corneal ulcer model associated with MC autotransplant was used. Sixteen, male or female, stray dogs suffered experimental corneal ulceration with sodium hydroxide soaked filter discs. After the lesions, animals were submitted to subconjunctival autotransplant of previously marked BM MC. The evaluation was made by immunofluorescence on the sixth day after lesions creation and histopathology was conducted 15 days after the same procedure, when it was possible to observe that the MC grafted in the injured area, the cells did not execute the homing process and, despite the inflammatory decrease, they did not help the corneal epithelial healing process in a short term evaluation. Thus, future studies about MC transplantations in corneal ulcers are indicated.
\end{abstract}

Key words: stem cell, bone marrow, mononuclear fraction, corneal ulcer, sodium hydroxide, dog.

\footnotetext{
IDepartamento de Medicina Animal, União Educacional do Planalto Central (UNIPLAC). SQN 108, B1 A, apt 302, 70744-010, Brasília, DF, Brasil. E-mail: gui tognoli@yahoo.com.br. Autor para correspondência.

"Programa de Pós-graduação em Medicina Veterinária, Universidade Federal de Santa Maria (UFSM), Santa Maria, RS, Brasil.

IIIDepartamento de Fisiologia Animal, Faculdade de Itapiranga (FAI), Itapiranga, SC, Brasil.

${ }^{\text {IV }}$ Departamento de Clínica de Pequenos animais (DCPA), UFSM, Santa Maria, RS, Brasil.

vLaboratório de Patologia Veterinária, Universidade de Brasília (UnB), Brasília, DF, Brasil.

${ }^{\mathrm{VI}}$ Curso de Medicina Veterinária, UnB, Brasília, DF, Brasil.
} 


\section{INTRODUÇÃO}

A úlcera de córnea é a oftalmopatia mais comum em cães, sendo que as úlceras superficiais resolvem-se rapidamente e com mínimas cicatrizes (STADES et al., 1999). No entanto, as úlceras profundas podem levar a déficits visuais devido à formação cicatricial ou à sinéquia anterior, se houver perfuração corneal ou ulceração severa, o que pode acarretar perda ocular por endoftalmite, glaucoma ou Pthisis bulbi (GELATT, 1991).

A transparência e a funcionalidade corneana são mantidas pelas CT límbicas (CTL) (SANGWAN, 2001), assim chamadas por terem sua localização no limbo e, frente a uma lesão destas, ocorre uma deficiência límbica, a qual cursa com conjuntivalização corneana (HUANG \& TSENG, 1991).

As etiologias para a deficiência das CTL são as queimaduras por base (NISHIWAKI-DANTAS et al., 2001), cicatriz ocular penfigóide, pterígio extenso recorrente (TI et al., 2002) neoplasias de superfície ocular, condições imunológicas e lesões por radiação (SANGWAN, 2001).

As úlceras estromais profundas requerem terapia agressiva, pois são potencialmente perigosas para a visão (GONÇALVES, 2000). Os tratamentos citados desta afecção são: recobrimento de terceira pálpebra com pálpebra superior; sutura da terceira pálpebra na conjuntiva dorsolateral; tarsorrafia; recobrimento com tecido conjuntival pediculado ou não; recobrimento com faixa conjuntival; com conjuntiva bulbar; técnicas de sutura corneana; transplante conjuntival livre; recobrimento com enxerto corneano lamelar; transplante livre de córnea a fresco (JENSEN, 1973; GELATT, 1991; STADES et al., 1999; GELAT 2003; SLATTER, 2005) ou preservada (GONÇALVES, 2000) e a ceratoplastia com fixação do enxerto por cola de cianoacrilato (BRAGA et al., 2004). No entanto, as alternativas citadas apresentam complicações pós-operatórias.

A fim de repor as CTL e melhorar a recuperação pós-operatória e a correção de resultados insatisfatórios, surge a pesquisa com CT, a qual abre perspectivas para terapias regenerativas que podem alterar o tratamento das doenças, pois constituem a fonte mais promissora de proliferação e diferenciação celular (NEIVA, 2005).

A fonte mais acessível para a terapia com CT são as CM obtidas da MO. Apesar da realização de pesquisas com essas células, ainda faltam estudos sobre métodos de purificação e expansão em cultura (ZAGO \& COVAS, 2004), marcação celular e sua identificação no pós-operatório (GOWDAK et al.,
2004) e definição de qual fração celular da MO apresenta maior plasticidade (HOWS, 2005). Por essa razão, autores propuseram que a utilização de um conjunto de células (como as $\mathrm{CM}$ ) é melhor que um único tipo celular, pois acredita-se que o primeiro dê suporte à proliferação e à manutenção das CT (GOWDAK et al., 2004).

O impasse da identificação após o implante começou a ser resolvido com o avanço da nanotecnologia, a qual tornou possível o desenvolvimento de nanocristais (NC), que revolucionaram a marcação celular (DUBERTRET et al., 2002). Os NC são marcadores fluorescentes, constituídos de materiais semi-condutores, resistentes e emissores de luz, pois mesmo medindo cerca de 2 a $6 \mathrm{~nm}$ podem ser facilmente detectados por microscopia de fluorescência ou citometria de fluxo (MATTHEAKIS et al., 2004).

As CM podem ser isoladas por meio da coleta da $\mathrm{MO}$, a qual deve ser submetida à filtração e centrifugação em um gradiente de densidade de $1.077 \mathrm{~g}$ $\mathrm{ml}^{-1}$ a $678 \mathrm{G}$ por 30 minutos, obtendo-se viabilidade e número celular acima de $90 \%$ e de 0,63 a $1,24.10^{8}$ células, respectivamente (TOGNOLI et al., 2007). Tais valores permitem o estudo do autotransplante em cães, pois além deste procedimento não disparar resposta do enxerto contra hospedeiro (VOLLWEILER et al., 2003), o número celular supera a quantidade mínima de $2 \times 10^{6}$ células preconizadas para a pega (GENGOZIAN, 2000). Associado a este número, a via intralesional aumenta a celularidade na lesão e evita a quimiotaxia das células transplantadas (VAQUERO et al., 2006).

O presente trabalho tem três objetivos: 1) avaliar a marcação celular com NC, 2) verificar a pega do autotransplante subconjuntival na região lesada com hidróxido de sódio $(\mathrm{NaOH})$ a $2 \mathrm{M}$ seis dias após o transplante (se essas mesmas células sofrerão migração para o olho contra lateral) e 3) comparar de maneira descritiva o padrão cicatricial dos grupos controle e tratado por histopatologia no período pósoperatório de 15 dias.

\section{MATERIAL E MÉTODOS}

Dezesseis cães machos ou fêmeas, sem raça definida, com peso em torno de $10 \mathrm{~kg}$, cedidos pelo Biotério Central da Universidade Federal de Santa Maria (UFSM), foram submetidos a tratamento antihelmíntico por via oral com pomoato de pirantel $\left(14,4 \mathrm{mg} \mathrm{kg}^{-1}\right)$, praziquantel $\left(5 \mathrm{mg} \mathrm{kg}^{-1}\right)$ e febantel $(15 \mathrm{mg}$ $\mathrm{kg}^{-1}$ ) e a um período de 30 dias de adaptação às condições locais, com consumo de ração e água $a d$ 
libitum durante o experimento. Após a adaptação, os animais foram separados em dois grupos (H e F), com dez e seis indivíduos, respectivamente, e submetidos à lesão por $\mathrm{NaOH}$ em ambos os olhos. Para a comparação da cicatrização corneana nos indivíduos do grupo $\mathrm{H}$, estes foram submetidos a exame histopatológico. Já nos animais do grupo $\mathrm{F}$ foram realizadas impressões sobre lâminas de imunofluorescência para detectar a presença de CM marcadas com NC (Figura 1a).

No período pré-cirúrgico foi realizado exame clínico para descartar doenças que contra-indicassem o procedimento. Os testes laboratoriais de hemograma, urinálise, bioquímica e pesquisa de hematozoários foram conduzidos no Laboratório de Análises Clínicas do Hospital Veterinário da UFSM. Após a avaliação inicial, foi realizado um exame oftalmológico que avaliou a superfície externa do bulbo e anexos, o teste lacrimal de Schirmer tipo $I^{\mathrm{a}}$, o teste com fluoresceína ${ }^{\mathrm{b}}$ (apenas nos animais do grupo $\mathrm{H}$ ), a tonometria de aplanação e a oftalmoscopia direta. Os animais se mostraram hígidos e foram admitidos no experimento.

Três dias antes do ato operatório, foram coletados $10 \mathrm{ml} \mathrm{kg}^{-1}$ de sangue da veia jugular de todos os animais, volume este conservado em bolsa de sangue contendo citrato de sódio, adenina, fosfato e dextrose e refrigerado a $4^{\circ} \mathrm{C}$, para a reposição volêmica no transoperatório, como proposto por TOGNOLI et al. (2007).

Vinte e quatro horas antes da intervenção, os animais foram submetidos a banho e tricotomia dos membros pélvicos desde a linha média da coluna vertebral até o terço distal da tíbia e próximo às veias jugular e cefálica e artéria metatarsiana. O jejum hídrico e alimentar foi de duas e 12 horas, respectivamente.

\section{Coleta de MO e preparação da lesão corneana}

Para a indução anestésica, utilizou-se propofol $^{\mathrm{c}}$ na dose de $5 \mathrm{mg} \mathrm{kg} \mathrm{kg}^{-1}$ pela via intravenosa (IV), sendo o acesso venoso mantido pela administração da solução de cloreto de sódio $(\mathrm{NaCl})$ $0,9 \%$ na dose de $10 \mathrm{ml} \mathrm{kg}^{-1} \mathrm{~h}^{-1}$. Após a indução, assegurou-se a via aérea por intubação orotraqueal, sendo este conectado a sistema anestésico semifechado para administração de uma mistura de isofluorano $^{\mathrm{d}}$ e oxigênio a $100 \%$. A monitoração anestésica consistiu de avaliação da freqüência cardíaca, eletrocardiografia, auscultação de bulhas cardíacas, ventilometria, pressão arterial invasiva, oximetria de pulso e temperatura corporal.

Com o animal posicionado na mesa cirúrgica em decúbito lateral direito, a anti-sepsia do campo operatório foi realizada com álcool-iodo-álcool e os panos de campo foram posicionados e fixados de maneira rotineira a fim de manter a técnica asséptica para a região de coleta de $\mathrm{MO}$.

Iniciadas as punções ósseas percutâneas na fossa trocantérica do fêmur esquerdo, com o objetivo de coletar $15 \mathrm{ml} \mathrm{kg}^{-1}$ de $\mathrm{MO}$, foram utilizadas uma agulha Steis $^{\mathrm{e}}$ e seringas de $20 \mathrm{ml}$ previamente heparinizadas ${ }^{f}$ para as aspirações. A MO foi acondicionada em bolsas de transplante de $\mathrm{MO}^{\mathrm{g}}$ previamente heparinizada com $0,1 \mathrm{ml}$ de heparina associado a $10 \mathrm{ml}$ de $\mathrm{NaCl} 0,9 \%$ para cada $100 \mathrm{ml}$ de MO a ser coletada.

O primeiro mililitro de MO coletado foi encaminhado para exame laboratorial, em que com $0,5 \mathrm{ml}$ da amostra foi avaliada a porcentagem de células nucleadas e a viabilidade celular com o corante azul de trypan em câmara de Neubauer, sendo considerada aceitável uma viabilidade superior a $70 \%$. Com o volume restante $(0,5 \mathrm{ml})$, foi realizado esfregaço para avaliação morfológica das células.

A determinação da viabilidade das células nucleadas foi realizada pela utilização de um tubo de hemólise individual, no qual $50 \mu 1$ de sangue de MO e volume igual de corante azul de trypan $1 \%$ foram homogeneizados. Após transferência de uma gota desta mistura para lâmina de microscopia, foi realizada a leitura em microscopia de luz, em que as células viáveis se apresentaram sem coloração e as células mortas coradas em azul. Para a avaliação morfológica das células da $\mathrm{MO}$, foram confeccionados esfregaços sobre lâmina de microscopia, as quais foram coradas com kit panótico rápido e avaliadas conforme a relação mielóide e eritróide de normo, hiper ou hipocelularidade da MO, excluindo-se do experimento os animais que apresentavam esta última condição. No entanto, nenhum animal apresentou-se nesta classificação.

Após a coleta da metade do volume de MO desejado, o sangue autólogo previamente armazenado foi administrado pela via IV. À obtenção do volume total, a solução de $\mathrm{MO}$ e $\mathrm{NaCl}$ heparinizada foi filtrada pelos filtros em linha de $850 \mu \mathrm{m}, 500 \mu \mathrm{m}$ e $200 \mu \mathrm{m}$ da bolsa de transplante de MO para remoção de espículas ósseas e êmbolos gordurosos. Após a passagem pelo primeiro filtro, MO heparinizada foi coletada para quantificação de células nucleadas, em que se esperava obter número superior a $2 \times 10^{8}$ células. A solução resultante foi acondicionada em bolsa de transplante de MO estéril para o transporte até o fluxo laminar, em que as $\mathrm{CM}$ da $\mathrm{MO}$ foram isoladas, incubadas e marcadas com NC como descrito no decorrer deste trabalho.

Concomitantemente ao isolamento e à marcação das CM, as lesões corneanas foram 


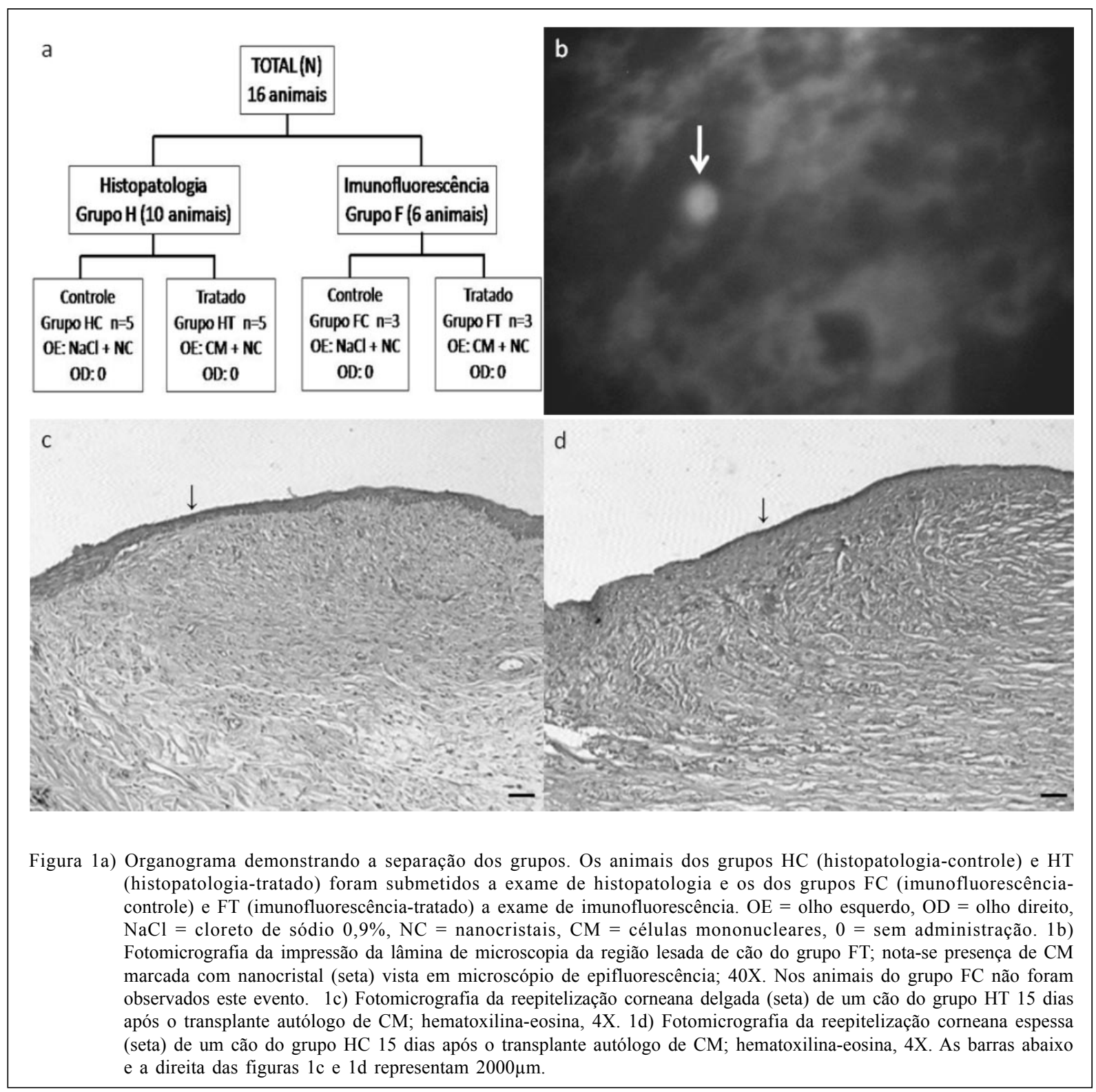

realizadas. Os animais foram reposicionados em decúbito esternal e tiveram as regiões ocular e periocular bilaterais preparadas com solução aquosa contendo $1 \%$ de iodo ativo ${ }^{\text {h }}$ e a colocação de panos de campo foi realizada. Para a centralização do bulbo após a colocação de blefarostato de Castroviejo, um bloqueio neuro-muscular foi conduzido com atracúrio na dose de $50 \mu \mathrm{g} \mathrm{kg}^{-1}$ pela via IV.

Para a realização das lesões corneanas experimentais, foi utilizada a técnica de discos circulares de papel filtro Whatman número $42^{\mathrm{j}}$ preconizada por LEVINSON et al. (1976), JUAN et al. (2003) e FECHINE-JAMACARU et al. (2005). Os discos de $6 \mathrm{~mm}$ foram embebidos em solução de $\mathrm{NaOH}$ a $2 \mathrm{M}$ por um período de 2 minutos. O excesso do líquido foi removido tocando-se o disco em gaze estéril para então serem posicionados na região dorsolateral da transição córneo-escleral em ambos os olhos por 2 minutos.

Decorrido o tempo preconizado, ambos os olhos foram lavados com $20 \mathrm{ml}$ de $\mathrm{NaCl} 0,9 \%$ e secos com cotonetes estéreis. Os animais do grupo $\mathrm{H}$ foram submetidos ao teste de fluoresceína para certificação da eficiência do modelo e extensão da lesão. Os cães pertencentes ao grupo F, no entanto, não foram submetidos a este procedimento para não haver falsospositivos na imunofluorescência realizada no período pós-operatório.

Após a criação das lesões oculares, foi administrado meloxicam na dose de $0,2 \mathrm{mg} \mathrm{kg}^{-1}$ pela via 
subcutânea e sulfato de morfina na dose de $0,1 \mathrm{mg} \mathrm{kg}^{-1}$ pela via epidural a fim de proporcionar analgesia pósoperatória imediata e maior conforto aos animais. Para prevenção de automutilação no período pósoperatório, em todos os indivíduos de ambos os grupos foram colocados colares elizabetanos.

\section{Isolamento das $\mathrm{CM}$}

Para o isolamento das $\mathrm{CM}$ foi utilizada a técnica de BOYUM (1968) modificada por TOGNOLI et al. (2007) pela qual, no interior de um fluxo laminar desinfetado com álcool $70 \%$ e luz ultravioleta, a MO coletada foi disposta em tubos Falcon de $50 \mathrm{ml}$ contendo gradiente de densidade ${ }^{\mathrm{k}} \mathrm{de} 1,077 \mathrm{~g} \mathrm{dl}^{-1}$, respeitando-se a proporção 1:1 de sangue:gradiente. A amostra foi centrifugada a $678 \mathrm{G}$ por 30 minutos à temperatura ambiente, processo que proporciona a separação das $\mathrm{CM}$, visíveis na forma de um halo na suspensão.

Após esse procedimento, com uma pipeta manual, o halo contendo as CM foi aspirado e submetido a três lavagens e centrifugações com soro fetal bovino e DMEM a $678 \mathrm{G}$ por 10 minutos, com o objetivo de remover o gradiente de densidade da solução.

Ao término das lavagens, foi obtido na porção final do tubo um botão (pellet) uniforme de $1000 \mu 1$, contendo as CM da MO, o qual foi resuspendido em $\mathrm{NaCl} 0,9 \%$, totalizando um volume de aproximadamente $3 \mathrm{ml}$. Essa suspensão foi então incubada com $1 \mu 1$ de NC (Qtracker ${ }^{\circledR} 655$ Cell labeling kit ${ }^{1}$ ) para cada $1,5 \mathrm{ml}$ de $\mathrm{CM}$ a ser administrada, agitada por 30 segundos no vórtex e levada à estufa à temperatura de $37^{\circ} \mathrm{C}$ por 45 minutos a fim de que as $\mathrm{CM}$ fossem marcadas (por endocitose dos marcadores) para posterior avaliação da presença nos tecidos estudados por meio imunofluorescência em um microscópio de epifluorescência com aumento de 40 vezes. Após a incubação, utilizando uma pipeta automática, foi retirada uma alíquota de $50 \mu 1$ da amostra para quantificação celular e para o teste de viabilidade celular utilizando o corante azul de trypan $1 \%$ para certificação que fossem transplantadas no mínimo $2 \times 10^{-6}$ células no local da lesão.

Uma segunda alíquota de $30 \mu 1$ foi coletada para certificação da marcação das CM pelos NC por microscopia epifluorescente. Para essa avaliação, os $10 \mu 1$ da fração celular foram colocados em um poço de lâmina para microscopia multispot, a qual foi submetida à secagem em temperatura ambiente. Posteriormente, as lâminas foram preparadas com solução salina tamponada com fosfato (PBS), glicerol e lamínula para posteriormente serem avaliadas por microscopia epifluorescente.
Inoculações e cuidados pós-operatórios

Após a separação das $\mathrm{CM}$ e a incubação com marcadores, os animais dos grupos HT e FT foram submetidos à anestesia tópica com colírio à base de cloridrato de tetracaína a $1 \%$ associado a cloridrato de fenilefrina a $0,1 \%$ e à administração das CM pela via subconjuntival no olho esquerdo (OE), após um período de aproximadamente 50 minutos após as confecções das lesões.

Os animais dos grupos $\mathrm{HC}$ e $\mathrm{FC}$ foram submetidos à anestesia tópica como descrito anteriormente e à injeção subconjuntival de $3 \mathrm{ml}$ de $\mathrm{NaCl}$ 0,9\% incubados com a mesma substância marcadora e suas células separadas foram enviadas a outros laboratórios da UFSM para pesquisas adicionais.

Para analgesia pós-operatória, utilizou-se meloxicam na dose de $0,1 \mathrm{mg} \mathrm{kg}^{-1}$ a cada 24 horas pela via subcutânea por quatro dias consecutivos e sulfato de morfina $0,5 \mathrm{mg} \mathrm{kg}^{-1}$ pela via intramuscular (IM) a cada oito horas por três dias consecutivos. Como terapia analgésica adicional, administrou-se colírio de atropina $1 \%$ três vezes ao dia durante todo o período de avaliação.

\section{Avaliação por imunofluorescência}

Seis dias após a administração subconjuntival, foi conduzida a avaliação da implantação da FCM marcadas com NC na região límbica de ambos os olhos dos animais do grupo FT e FC. Essa análise constou da realização de anestesia tópica e impressão em lâmina de microscopia dos locais lesionados, as quais foram posteriormente contracoradas com Evans blue por quatro minutos. As lâminas foram então submetidas a procedimento de lavagem com PBS e água destilada. Depois foi realizada a secagem e a montagem foi procedida com uma gota de PBS e glicerol na proporção 1:1, com a colocação posterior de lamínula sobre a impressão. As avaliações foram conduzidas no Laboratório de Virologia do Departamento de Medicina Veterinária Preventiva da UFSM. Nesta etapa um único avaliador valendo-se de um microscópio de epifluorescência no aumento de 40 vezes verificou a presença de células marcadas.

\section{Avaliação histopatológica}

Passados 15 dias da administração das CM marcadas, os animais dos grupos HC e HT foram submetidos à eutanásia por meio de pré-medicação com acepromazina $\left(0,1 \mathrm{mg} \mathrm{kg}^{-1}\right)$ e morfina $\left(1 \mathrm{mg} \mathrm{kg}^{-1}\right)$ pela via IM, indução anestésica com tiopental sódico $\left(15 \mathrm{mg} \mathrm{kg}^{-1}\right)$ pela via IV e, após entrada em plano anestésico profundo, foi administrada rapidamente uma 
ampola de $10 \mathrm{ml}$ cloreto de potássio a $10 \%$ pela mesma via.

As regiões córneo-esclerais lesionadas foram coletadas e fixadas em formol tamponado a $10 \%$ por um período mínimo de 10 dias e emblocadas em parafina para a realização dos cortes de microscopia com auxílio de um micrótomo. Os cortes histológicos das amostras foram dispostos sobre lâminas de microscopia e então coradas com hematoxilina-eosina para avaliação histopatológica.

A leitura das lâminas foi executada no Laboratório de Patologia Veterinária da Universidade de Brasília, quando foram coletados os dados sobre a córnea (inflamação, presença de reepitelização, espessura, angiogênese e presença de pigmentação) e limbo (inflamação e angiogênese) por um único avaliador, dispondo de um microscópio óptico conectado a um sistema de captura de imagens.

\section{RESULTADOS E DISCUSSÃO}

Isolamento de células mononucleares

A técnica descrita de isolamento, quantificação e teste de viabilidade das CM permitiu a obtenção de 1,34 a $9,5 \times 10^{7}$ células (média de $5 \times 10^{7}$ ), com viabilidade entre 88 e $97 \%$ (média de 95,3\%), números já relatados por TOGNOLI et al. (2007) e considerados adequados para a pega do autotransplante (GENGOZIAN, 2000). A quantificação das células poderia ser realizada por citometria de fluxo, no entanto, esta técnica demanda mão-de-obra especializada e alto gasto com aparelhagem (NAKAGE et al., 2005).

Após isolamento e quantificação das CM, a administração se deu por via subconjuntival, pois esta promove alta concentração no tecido corneano (SLATTER, 2005) e, se injetadas pela via intralesional como indicado por ANDERSON et al. (2005), poderia prejudicar o paralelismo das lamelas corneanas.

Avaliação da localização das CM por imunofluorescência direta

Apesar de a dificuldade para localizar as CM após o transplante (GOWDAK et al., 2004), a utilização dos NC na marcação celular permite que os marcadores não sejam passados para células adjacentes, mas que os NC sejam transferidos para até seis gerações de células-filhas, sem gerar toxicidade, o que não altera a funcionalidade celular (INVITROGEN, 2007). Ao permitir essa marcação por seis gerações e tendo em vista que as figuras mitóticas límbicas são geradas a cada 24 horas (WILCOCK, 2005), o tempo transcorrido da administração das CM até a avaliação pela imunofluorescência foi de seis dias.

A avaliação foi realizada por imunofluorescência direta da impressão sobre lâmina da região lesada, em que $100 \%(n=3)$ dos olhos tratados (OE) dos animais do grupo FT apresentaram CM marcadas (Figura 1b). Já os olhos contralaterais $(n=3)$ dos mesmos animais não apresentaram eventos de fluorescência. Os animais do grupo FC que foram submetidos à administração de $\mathrm{NaCl} 0,9 \%$ incubado com NC no OE não apresentaram eventos em ambos os olhos. Isso sugere que o marcador não proporcionou resultados falso-positivos e que as CM marcadas administradas pela via subconjuntival no OE dos animais do grupo FT não sofreram quimiotaxia para o OD.

Avaliação histopatológica

À análise da resposta inflamatória dos diferentes grupos, nota-se que dos cinco animais que receberam administração de $\mathrm{NaCl}$ 0,9\% incubado com $\mathrm{NC}, 60 \%(\mathrm{n}=3)$ apresentaram inflamação leve e $40 \%$ $(n=2)$ inflamação moderada do local. Dos cinco animais que foram submetidos ao tratamento com CM, 20\% $(n=1)$ não apresentaram inflamação e $80 \%(n=4)$ demonstraram inflamação ocular leve, o que constitui achado importante, uma vez que no trabalho de BRUNELLI et al. (2006) houve inflamação leve em $33,3 \%$, moderada em $22,2 \%$ e severa em $44,4 \%$. Já nos olhos contralaterais [olhos direitos (OD) dos animais de ambos os grupos], observou-se que $10 \%(\mathrm{n}=1)$ não apresentavam inflamação, contra $70 \%(n=7) \mathrm{com}$ inflamação leve e 20\% ( $n=2)$ com inflamação moderada. Assim, sugere-se que as CM colaboram como mediadores da inflamação ocular por diminuição deste processo nos animais tratados.

Em relação à reepitelização, 100\% dos animais ( $\mathrm{n}=10$, ou 20 olhos avaliados) apresentaram essa condição com diferentes graus de resposta, pois dos cinco bulbos que receberam administração subconjuntival de $\mathrm{NaCl} 0,9 \%$ incubados com NC 20\% $(n=1)$ apresentaram epitélio corneano delgado, $40 \%$ $(n=2)$ moderado e $40 \%(n=2)$ espesso. Os cinco olhos submetidos ao transplante subconjuntival de $\mathrm{CM}$ incubadas com NC apresentaram-se da seguinte forma: $80 \%(n=4)$ com epitélio corneano de espessura delgada e $20 \%(n=1)$ moderada e $0 \%(n=0)$ espessa. Já os dez olhos que não receberam administrações subconjuntivais, $50 \%(\mathrm{n}=5)$ demonstraram fino epitélio corneano, $10 \%(n=1)$ moderado e $40 \%(n=4)$ com epitélio espesso. Desse modo, o transplante de CM parece influenciar negativamente a regeneração do epitélio corneano (Figura 1c e 1d). 


\section{CONCLUSÕES}

Os NC são marcadores celulares eficientes a curto prazo para avaliar a presença de CM administradas pela via subconjuntival no tratamento experimental de úlcera de córnea por substância de caráter básico em cães, pois permitiram confirmar a presença das CM transplantadas.

Quando as CM foram administradas pela via subconjuntival em cães, elas não sofrem processo de quimiotaxia para o olho lesado contra-lateral e não auxiliam no processo de cicatrização corneana da úlcera induzida experimentalmente por $\mathrm{NaOH}$ a $2 \mathrm{M}$ no período de 15 dias.

Apesar de as CM in natura não influenciarem de maneira positiva, a curto prazo, a cicatrização da úlcera de córnea experimentalmente induzida por $\mathrm{NaOH}$, estudos sobre o potencial de diferenciação, a diminuição do processo inflamatório e a funcionalidade destas células devem ser realizados.

\section{FONTES DE AQUISIÇÃO}

aTeste de Schimer Ophthalmos - Ophthalmos

${ }^{\text {b}}$ Fluoresceína Strips Ophthalmos - Ophthalmos

'Diprivan 1\% - AstraZeneca do Brasil

'Isoflurane - Cristália

${ }^{\mathrm{e} A g u l h a}$ Steis - Tucumedy

fLiquemine - Roche

${ }^{g}$ Bone Marrow Collection Kit - Baxter Hospitalar

hiodeíne - Rioquímica

'Tracrium - GlaxoSmithKline

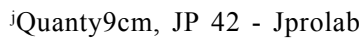

${ }^{k}$ Histopaque 1077 - Sigma

${ }^{1}$ Qtracker 655 - Invitrogen

\section{COMITÊ EM ÉTICA E BIOSSEGURANÇA}

Este trabalho foi aprovado pelo Comitê de Ética em Pesquisa (CEP) da UFSM sob o processo número 23081.007106/2006-81, em 05 de junho de 2006.

\section{REFERÊNCIAS}

ANDERSON, D. et al. Cell-based therapy for disc repair. Spine Journal, v.5, p.297-303, 2005.

BOYUM, A. Isolation of mononuclear cells and granulocytes form human blood: isolation of mononuclear cells by one centrifugation, and of granulocytes by combining centrifugation and sedimentation at $1 \mathrm{~g}$. Scandinavian Journal of Clinical and Laboratory Investigation. Supplementum, v.97, p.77-89, 1968.

BRAGA, F.V.A. et al. Ceratoplastia com enxerto autógeno lamelar livre de córnea e pediculado de conjuntiva fixados com adesivo de cianoacrilato em cães. Ciência Rural, v.34, n.4, p.1119-1126, 2004.

BRUNELLI, A. T.J. et al. Excision of sclerocorneal limbus in dogs and resulting clinical events. Study of an experimental model. Arquivo Brasileiro de Medicina Veterinária e Zootecnia, v.58, n.1, p.52-58, 2006.

DUBERTRET, B. et al. In vivo imaging of quantum dots encapsulated in phospholipid micelles. Science, v.298, p.1759-1762, 2002 .

FECHINE-JAMACARU, F.V. et al. Modelo de angiogênese inflamatória em córnea de coelho induzida pela cauterização alcalina pontual. Acta Cirúrgica Brasileira, v.20, n.1, p.64-73, 2005.

GELATT, K.N. Veterinary ophthalmology. Philadelphia: Lea \& Febinger, 1991. 765p.

GELATT, K.N. Doenças e cirurgias da córnea e esclera do cão. In: Manual de oftalmologia veterinária. São Paulo: Manole, 2003. Cap.7, p.125-164.

GENGOZIAN, N. Identification and isolation of hematopoietic progenitors. In: FELDMAN, B.F. et al. Schalm's veterinary hematology. Philadelphia: Williams \& Wilkins, 2000. Cap.16, p.91-96.

GONÇALVES, G.F. Ceratoplastia lamelar homóloga em cão com conservação em solução super saturada de açúcar ou glicerina. 2000. 54f. Dissertação (Mestrado em Medicina Veterinária) - Universidade Federal de Santa Maria, Santa Maria.

GOWDAK, L.H.W. et al. Análise crítica da utilização de células-tronco no tratamento da insuficiência cardíaca. Revista da Sociedade de Cardiologia do Estado de São Paulo, v.14, n.1, p.179-185, 2004.

HOWS, J. Adult stem cell therapy beyond haemopoietic stem cell transplantation? An update. Transplant Immunology, v.14, p.221-223, 2005.

HUANG, A. J.W.; TSENG, S.C.G. Corneal epithelial wound healing in the absence of limbal epithelium. Investigative Ophthalmology \& Visual Science, v.32, n.1, p.96-105, 1991.

INVitrogen. Cellular analysis. Biology in context. California, 2007. 634p.

JENSEN, H.E. Stereoscopic atlas of ophthalmic surgery of domestic animals. Saint Louis: Mosby, 1973. 145p.

JUAN, Y. et al. Effect of exogenous mesenchymal stem cells on wound healing following corneal alkali burn. Investigative Ophthalmology \& Visual Science, v.44, p.891, 2003.

LEVINSON, R.A. et al. Ascorbic acid prevents corneal ulceration and perforation following experimental alkali burs. Investigative Ophthalmology, v.15, n.12, p.986-993, 1976.

MATTHEAKIS, L.C. et al. Optical coding of mammalian cells using semiconductor quantum dots. Analytical Biochemistry, v.327, p.200-208, 2004.

NAKAGE, A. P. et al. Metodologia e aplicação da citometria de fluxo na hematologia veterinária. Ciência Rural, v.35, n.4. p.966-973, 2005. 
NEIVA, P. Células que salvam vidas. Revista Veja, n.1932, p.118-126, 2005.

NISHIWAKI-DANTAS, M.C. et al. Ipsilateral limbal translocation for treatment of partial limbal deficiency secondary to ocular alkali burn. British Journal of Ophthalmology, v.85, n.9, p.1031-1033, 2001.

SANGWAN, V.S. Limbal stem cells in health and disease Bioscience Reports, v.21, n.4, p.385-405, 2001.

SLATTER, D. Córnea e esclera. In Fundamentos de oftalmologia veterinária. São Paulo: Roca, 2005. Cap.11, p.283-338.

STADES, C.F. et al. Fundamentos de oftalmologia veterinária. São Paulo: Manole, 1999. 203p.

TI, S.E. et al. Factors affecting outcome following transplantation of ex vivo expanded limbal epithelium on amniotic membrane for total limbal deficiency in rabbits. Investigative Ophthalmology \& Visual Science, v.43, n.8, p.2584-2592, 2002
TOGNOLI, G.K. et al. Isolamento, quantificação e viabilidade da fração total de células mononucleares da medula óssea em cães. In: CONGRESSO BRASILEIRO DA ANCLIVEPA, 28., 2007, Florianópolis. Anais... Porto Alegre: Acta Scientiae Veterinariae, 2007. V.35, suplemento, p.228-230.

WILCOCK, B. Patologia geral do olho. In: SLATTER, D. Fundamentos de oftalmologia veterinária. São Paulo: Roca, 2005. Cap.4, p.77-96.

VAQUERO, J. et al. Cell therapy using bone marrow stromal cells in chronic paraplegic rats. Systemic or local administration? Neuroscience Letters, v.398, p.129-134, 2006 .

VOLLWEILER, J.L. et al. Hematopoietic stem cell gene therapy: progress toward therapeutic targets. Bone Marrow Transplantation, v.32, p.1-7, 2003.

ZAGO, M.A.; COVAS, D.T. Pesquisas com células-tronco: aspectos científicos, éticos e sociais. In: SEMINÁRIO DO INSTITUTO FERNANDO HENRIQUE CARDOSO, 2004, São Paulo. Anais... São Paulo: Instituto Fernando Henrique Cardoso, 2004. 23p. 